\title{
C1q/TNF-related protein 4 restores leptin sensitivity by downregulating NF-KB signaling and microglial activation
}

\author{
Liu Ye ${ }^{1 \dagger}$, Gongwei Jia ${ }^{1 \dagger}$, Yuejie Li ${ }^{1}$, Ying Wang ${ }^{1}$, Hong Chen ${ }^{2}$, Lehua $\mathrm{Yu}^{1+}$ and Dandong $\mathrm{Wu}^{1{ }^{* \dagger}}$ (D)
}

\begin{abstract}
Objective: C1qTNF-related protein 4 (CTRP4) acts in the hypothalamus to modulate food intake in diet-induced obese mice and has been shown to exert an anti-inflammatory effect on macrophages. Since high-fat diet-induced microglial activation and hypothalamic inflammation impair leptin signaling and increase food intake, we aimed to explore the potential connection between the anorexigenic effect of CTRP4 and the suppression of hypothalamic inflammation in mice with DIO.
\end{abstract}

Methods: Using an adenovirus-mediated hypothalamic CTRP4 overexpression model, we investigated the impact of CTRP4 on food intake and the hypothalamic leptin signaling pathway in diet-induced obese mice. Furthermore, central and plasma proinflammatory cytokines, including TNF- $\alpha$ and IL-6, were measured by Western blotting and ELISA. Changes in the hypothalamic NF-KB signaling cascade and microglial activation were also examined in vivo. In addition, NF-KB signaling and proinflammatory factors were investigated in BV-2 cells after CTRP4 intervention.

Results: We found that food intake was decreased, while leptin signaling was significantly improved in mice with DIO after CTRP4 overexpression. Central and peripheral TNF- $a$ and IL-6 levels were reduced by central Ad-CTRP4 administration. Hypothalamic NF-kB signaling and microglial activation were also significantly suppressed in vivo. In addition, NF-kB signaling was inhibited in BV-2 cells following CTRP4 intervention, which was consistent with the decreased production of TNF- $a$ and IL-6.

Conclusions: Our data indicate that CTRP4 reverses leptin resistance by inhibiting NF-KB-dependent microglial activation and hypothalamic inflammation.

Keywords: CTRP4, Leptin signaling, Microglial activation, NF-KB signaling, Diet-induced obesity

\section{Background}

In anorexigenic proopiomelanocortin/cocaine- and amphetamine-regulated transcript (POMC/CART) neurons and orexigenic agouti-related peptide/neuropeptide Y (AgRP/NPY) neurons, the hypothalamic leptin

\footnotetext{
*Correspondence: facia2010@126.com

${ }^{+}$Liu Ye and Gongwei Jia contributed equally to this work.Lehua Yu and Dandong Wu contributed equally to this work.

'Department of Rehabilitation, The Second Affiliated Hospital of Chongqing Medical University, 76 Linjiang Road, Yuzhong District, Chongqing 400010, China

Full list of author information is available at the end of the article
}

signaling pathway plays a key role in the regulation of food intake and energy balance [1]. Leptin signaling is often impaired by high-fat diet (HFD)-induced hypothalamic inflammation [2,3]. Although metabolic inflammation in the medial basal hypothalamus $(\mathrm{MBH})$ is characterized by the accumulation of astrocytes and microglia, the latest research showed that microglia are essential players in the saturated fat diet-induced inflammatory process [4]. Even during the early course of HFD feeding, microglial recruitment, proliferation, and size changes occurred in conjunction with altered

C C The Author(s). 2021 Open Access This article is licensed under a Creative Commons Attribution 4.0 International License, which permits use, sharing, adaptation, distribution and reproduction in any medium or format, as long as you give appropriate credit to the original author(s) and the source, provide a link to the Creative Commons licence, and indicate if changes were made. The images or other third party material in this article are included in the article's Creative Commons licence, unless indicated otherwise in a credit line to the material. If material is not included in the article's Creative Commons licence and your intended use is not permitted by statutory regulation or exceeds the permitted use, you will need to obtain permission directly from the copyright holder. To view a copy of this licence, visit http://creativecommons.org/licenses/by/4.0/. The Creative Commons Public Domain Dedication waiver (http://creativecommons.org/publicdomain/zero/1.0/) applies to the data made available in this article, unless otherwise stated in a credit line to the data. 
morphology [5]. Moreover, activated microglia induce neurotoxic effects by producing inflammatory cytokines, including tumor necrosis factor- $\alpha$ (TNF- $\alpha$ ), interleukin- 6 (IL-6), and interleukin-1 $\beta$ (IL-1 $\beta$ ) $[6,7]$. In addition, several inflammatory pathways were shown to be upregulated [8], including the classic proinflammatory ІкB $\alpha$ (inhibitor of $\kappa B$ ) kinase $\beta /$ nuclear factor kappa B (IKK $\beta$ / NF- $к B$ ) signaling pathway [8]. More interestingly, studies have shown that inhibiting the NF- $\mathrm{kB}$ cascade in microglia reduces microgliosis and diet-induced weight gain $[4,9]$ and restores hypothalamic leptin sensitivity [10], suggesting a promising therapeutic target for HFDinduced obesity.

The CTRP (also referred to as C1qTNF-related protein) family, which features a highly conserved Cterminal complement $\mathrm{C} 1 \mathrm{q}$ domain [11], belongs to the adipokine family [12]. It plays important roles in multiple physiological processes, such as inflammation and metabolism [13, 14]. For example, CTRP1 plays an essential role in linking dysregulated lipid metabolism and inflammatory responses in macrophages [15]. Among the CTRP family, CTRP4 is unique in possessing two C1q domains connected by a short linker and acts in the hypothalamus to modulate food intake [16]. It has been demonstrated that central injection of CTRP4 could decrease food intake in mice with diet-induced obesity (DIO); however, the underlying mechanism remains largely unknown [16]. Given that CTRP4 is able to suppress lipopolysaccharide (LPS)-induced proinflammatory cytokine production in macrophages by reducing NF- $\mathrm{KB}$ and signal transducer and activator of transcription 3 (STAT3) activation [17], there may be a connection between the anorexigenic effect of CTRP4 and hypothalamic inflammation in mice with DIO.

In the present study, we aimed to investigate whether CTRP4 regulated food intake in mice with DIO by suppressing hypothalamic inflammation. We examined whether CTRP4 exerted its anti-inflammatory effects by attenuating microglial activation and inhibiting the NF$\kappa \mathrm{B}$ pathway, which ultimately led to improved leptin signaling and reduced food intake.

\section{Methods}

\section{Construction and amplification of recombinant} adenoviruses

Recombinant adenoviruses were generated by using AdEasy technology as previously described [18]. Full fragments of murine C1qtnf4 (NM_026161.3) were PCRamplified and subcloned into pAdTrack-CMV. The resultant shuttle vectors were used to generate recombinant adenoviral vectors through homologous recombination with the adenoviral backbone vector in bacterial BJ5183 cells. Subsequently, the recombinant adenovirus AdCTRP4 was generated in HEK-293 cells. The resulting
Ad-CTRP4 adenoviruses coexpressed GFP as a marker to track infection efficiency.

\section{Animals}

A total of 130 C57BL/6 male mice (6 8 weeks of age; $18 \sim 23 \mathrm{~g}$ ) were used in this study. All mice were housed in temperature-controlled polycarbonate cages (Animal Center of Chongqing Medical University, Chongqing, China) with unlimited access to food and water throughout the study period. During the first week, all mice were fed a standard chow diet (SCD, 10\% kcal derived from fat). One week later, the mice were randomly divided into SCD-fed group or high-fat diet (HFD, 60\% kcal derived from fat, catalog no. D12492, Research Diets, USA)-fed group. The mice received SCD or HFD for another 20 weeks before the experiments. All animal protocols were approved by the Animal Experimentation Ethics Committee of Chongqing Medical University.

\section{Stereotaxic cannulation}

As previously described, the mice were anesthetized and fixed in a stereotactic apparatus. A unilateral 26-gage guide cannula was implanted into the third ventricle. The stereotaxic coordinates were $0.83 \mathrm{~mm}$ anterior and $0 \mathrm{~mm}$ right lateral to the bregma and $4.8 \mathrm{~mm}$ ventral to the skull. After the animals recovered from surgery (when the body weight of the mice recovered to $90 \%$ of their preoperative weight, about 7 days), baseline food intake (for $24 \mathrm{~h}$ ) was measured. SCD-fed mice were treated i.c.v. with saline $(3 \mu \mathrm{L})(\mathrm{SCD}$-saline $(\mathrm{SCS}))$ as the control group $(\mathrm{n}=10)$. HFD-fed mice were randomized into the following three groups: (1) HFD-saline (HFS) (n = 10), (2) HFD-Ad-GFP (HFG) ( $\mathrm{n}=10)$, (3) HFD-AdCTRP4 (HFC) $(\mathrm{n}=10)$. The mice were treated i.c.v. with Ad-CTRP4 $\left(3 \mu \mathrm{L}, 10^{10} \mathrm{pfu}\right)$, Ad-GFP $\left(3 \mu \mathrm{L}, 10^{10} \mathrm{pfu}\right)$, or saline $(3 \mu \mathrm{L})$ at a flow rate of $0.1 \mu \mathrm{L} / \mathrm{min}$. Seventy-two hours after i.c.v. intervention [18], the mice were anesthetized, plasma and tissue samples were collected for further molecular analysis. In vivo experiments were performed without blinding of the investigators.

\section{Leptin sensitivity assay}

To study the changes of leptin sensitivity, another set of experiment was performed. Sixty hours after central intervention, mice were fasted for $12 \mathrm{~h}$, then either vehicle (saline) or leptin (3 $\mu \mathrm{g} / \mathrm{mice})$ was i.c.v. injected [19]. Fifteen minutes later, the mice were anesthetized, and tissues were collected for further analysis.

\section{Seven-day-phase food intake in conscious mice}

NCD- and HFD-fed mice were individually housed in their familiar housing cages and fed ad libitum. Before the start of the dark cycle, each mouse received onetime i.c.v. injection. NCD-fed mice were infused with 
saline $(3 \mu \mathrm{L})$ and HFD-fed mice were infused with saline $(3 \mu \mathrm{L})$, Ad-GFP $\left(3 \mu \mathrm{L}, 10^{10} \mathrm{pfu}\right)$, or Ad-CTRP4 $(3 \mu \mathrm{L}$, $\left.10^{10} \mathrm{pfu}\right)$. Food intake and body weight were monitored every 24 h for 7 days.

\section{Determination of plasma parameters}

Seventy-two hours after i.c.v. intervention, fasting blood samples were collected retro-orbitally. Plasma was separated by centrifugation and stored at $-80{ }^{\circ} \mathrm{C}$ for plasma parameter analysis. Serum levels of total cholesterol (TC), triglycerides (TG), glycosylated serum protein (GSP), high-density lipoprotein cholesterol (HDL-c), and low-density lipoprotein cholesterol (LDL-c) were measured with enzymatic colorimetric kits. Plasma glucose was measured by the glucose oxidase method. Plasma TNF- $\alpha$ and IL- 6 were measured by ELISA kits (No. 887324 and No. 88-7064, Invitrogen, Carlsbad, CA, USA).

\section{Cell culture and treatments}

BV-2 microglial cells (Zhong Qiao Xin Zhou Biotechnology Co., Ltd., Shanghai, China) were cultured in Dulbecco's modified Eagle's medium (DMEM) (D6046, SigmaAldrich, St. Louis, MO, USA) supplemented with $10 \%$ heat-inactivated fetal bovine serum (FBS) and $1 \%$ penicillin-streptomycin. Cells were maintained at $37{ }^{\circ} \mathrm{C}$ in a humidified $5 \% \mathrm{CO}_{2}$ incubator. BV-2 microglia were grown to $70 \%$ confluence before treatment. To determine the appropriate concentration of palmitate, the cells were treated by replacing the media with fresh media containing $50 \mu \mathrm{M}, 100 \mu \mathrm{M}$, or $200 \mu \mathrm{M}$ palmitate (PA) (N0830, MCE, NJ, USA) or dimethyl sulfoxide (DMSO). Six groups were set as follows: control group, CTRP4 2.5 group, PA group, PA+CTRP4 2.5 group, PA+CTRP4 5 group, and PA+CTRP4 10 group. Recombinant murine CTRP4 protein (2137-TN-050, Novus Biologicals, CO, USA) was diluted to $2.5 \mu \mathrm{g} / \mathrm{ml}, 5 \mu \mathrm{g} / \mathrm{ml}$, and $10 \mu \mathrm{g} / \mathrm{ml}$ in DMEM. Each cell culture plate was preincubated with different concentrations of recombinant murine CTRP4 protein for $2 \mathrm{~h}$ as indicated in the figure legend. After $2 \mathrm{~h}$ of pretreatment, the cells were treated with $100 \mu \mathrm{M}$ PA for $24 \mathrm{~h}$ before analysis.

\section{Immunofluorescence analysis}

Seventy-two hours after i.c.v. Ad-CTRP4, Ad-GFP, or saline injection, the mice were anesthetized by $50 \mathrm{mg} / \mathrm{kg}$ sodium pentobarbital (i.p.) and perfused first with saline containing 20 units $/ \mathrm{mL}$ heparin for $3 \mathrm{~min}$ and then with $4 \%$ paraformaldehyde in $0.1 \mathrm{~mol} / \mathrm{L}$ PBS for $20 \mathrm{~min}$, as previously described [18]. Then, the hypothalamus was separated, embedded in optimal cutting temperature compound, immediately frozen on dry ice, and stored at $-80{ }^{\circ} \mathrm{C}$. In vitro, BV-2 microglial cells were seeded onto glass coverslips. The samples were fixed in $4 \%$ paraformaldehyde, permeabilized with $0.1 \%$ Triton X-100, and incubated with a 1:500 dilution of primary antibodies against ionized calcium-binding adapter molecule 1 (Iba1) (Wako Pure Chemical Industries, Ltd., Japan), phospho-P65 (Ser536) (3033, Cell Signaling Technology, Beverly, MA, USA), P65 (8242, Cell Signaling Technology, Beverly, MA, USA), NPY (11976, Cell Signaling Technology, Beverly, MA, USA), POMC (ab210605, Abcam, Cambridge, MA, USA), and CD68 (53444, Abcam, Cambridge, MA, USA). Then, the sections were incubated in fluorescent-conjugated secondary antibodies: goat anti-mouse IgG (DyLight 549, Abbkine, Wuhan, China) and goat anti-rabbit IgG (DyLight 488, Abbkine, Wuhan, China). DNA was stained with 4',6diamidino-2-phenylindole (DAPI). Images were captured with a Nikon TE2000U microscope. For Iba1, POMC, NPY, p-P65, P65, and Iba1/CD68 immunostaining in which discrete cells could be identified, cell number was counted manually using ImageJ. For microglia cell size (using Iba1), thresholding was performed in ImageJ, followed by densitometric quantification [2].

\section{Western blot analysis}

Seventy-two hours after i.c.v. Ad-CTRP4, Ad-GFP, or saline injection, samples were harvested from the mice. The hypothalamus was dissected as previously described [18]. Hypothalamus tissues were homogenized. Total protein was extracted using radioimmunoprecipitation assay lysis buffer. Nuclear and cytoplasmic fractions were isolated using an Ne-PER nuclear and cytoplasmic extraction reagent kit (Thermo Scientific, MA, USA). The proteins were extracted in lysis buffer, subjected to $8 \%$ SDS-PAGE and transferred to polyvinylidene difluoride membranes. The membranes were probed at $4{ }^{\circ} \mathrm{C}$ in the presence of primary antibodies against phospho-P65 (Ser536) (3033, Cell Signaling Technology, Beverly, MA, USA), P65 (8242, Cell Signaling Technology, Beverly, MA, USA), phospho-IKK $\alpha / \beta$ (Ser176/180) (2697, Cell Signaling Technology, Beverly, MA, USA), IKK $\alpha / \beta$ (2678, Cell Signaling Technology, Beverly, MA, USA), phospho-IкB $\alpha$ (Ser32/36) (9246, Cell Signaling Technology, Beverly, MA, USA), CTRP4 (36871, Abcam, Cambridge, MA, USA), POMC (210605, Abcam, Cambridge, MA, USA), phosphoJanus kinase 2 (JAK2) (32101, Abcam, Cambridge, MA, USA), phospho-STAT3 (Tyr705) (9145, Cell Signaling Technology, Beverly, MA, USA), STAT3 (9139, Cell Signaling Technology, Beverly, MA, USA), suppressor of cytokine signaling 3 (SOCS3) (2932, Cell Signaling Technology, Beverly, MA, USA), TNF- $\alpha$ (11948, Cell Signaling Technology, Beverly, MA, USA), IL-6 (12912, Cell Signaling Technology, Beverly, MA, USA), NPY (11976, Cell Signaling Technology, Beverly, MA, USA), CD11b (66519-1-1g, 
Proteintech, Bath, UK), Lamin B1 (12987-1, proteintech, Suite Rosemont, IL, USA), and CD68 (53444, Abcam, Cambridge, MA, USA). After being washed three times with Tris-buffered saline containing $0.1 \%$ Tween-20, the membranes were incubated with secondary antibodies for $1 \mathrm{~h}$ at room temperature. Next, the blots were visualized with a Bio Imaging System Densitometer (Bio-Rad, Hercules, CA), and quantification of antigen-antibody complexes was performed with Quantity One analysis software (Bio-Rad).

\section{Statistical analysis}

By using PASS 15.0 (NCSS, Utah, USA), the sample size was calculated after analyzing data from our pilot study. To detect differences in food intake at the third day after i.c.v. injection and molecular analysis among groups with a two-tailed $\alpha$ error of $5 \%$, a $\beta$ error of $20 \%, \geq 5$ animals per group were required. The data are presented as the mean \pm standard deviation (SD). Statistical analyses were performed using SPSS 23.0 (SPSS, Chicago, IL). A twotailed unpaired Student's $t$ test or the Mann-Whitney test, as appropriate, was used for two-group comparisons. One-way or two-way analysis of variance (ANOVA) and Tukey's test for multiple comparisons were used to analyze differences between groups. A value of $\mathrm{P}<0.05$ was considered significant.

\section{Results}

Effects of hypothalamic CTRP4 overexpression on energy homeostasis and body metabolism

Twenty weeks of HFD consumption significantly decreased hypothalamic CTRP4 expression. Hypothalamic CTRP4 protein levels were increased $(\mathrm{P}<0.05)$ in HFD-fed mice after i.c.v. Ad-CTRP4 injection compared with the controls (Fig. 1a-b). Then, we explored the effects of CTRP4 on energy homeostasis and revealed that central Ad-CTRP4 intervention caused significant decreases in food intake in HFD-fed mice between days 2 and 7 (Fig. 1c). While there was no significant difference in total body weight between the HFD-fed groups due to the short intervention period (data not shown), i.c.v. Ad-CTRP4 injection significantly

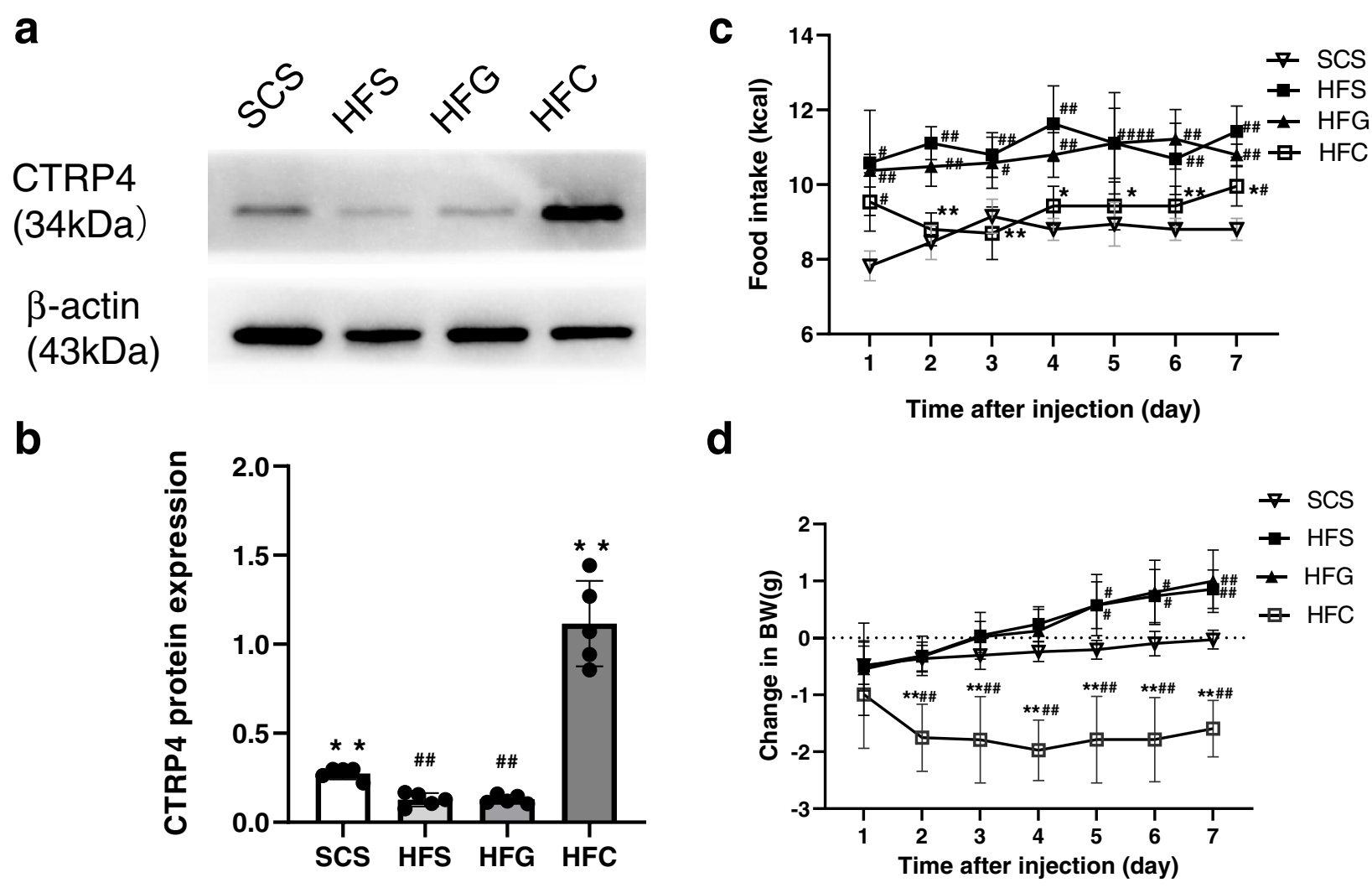

Fig. 1 Effects of central Ad-CTRP4 injection on hypothalamic CTRP4 protein expression, food intake, and body weight in mice. (a-b) At $72 \mathrm{~h}$ after i.c.v. injection, hypothalami were collected from mice fed a standard chow diet (SCD) or a high-fat diet (HFD). Representative Western blot (a) and quantitative analysis of CTRP4 expression (b) in the hypothalamus of mice that received saline (SCS and HFS), Ad-GFP (HFG), and Ad-CTRP4 (HFC). (c) Daily food intake after central intervention. (d) Changes in body weight after central intervention. The data are the mean \pm SD. $n=5$ per group. Two-way analysis of variance (ANOVA) and Tukey's test for multiple comparisons were used to analyze differences among groups. ${ }^{\#}<<$ $0.05,{ }^{\# \#} \mathrm{P}<0.01$ vs. SCS group, ${ }^{*} \mathrm{P}<0.05,{ }^{* *} \mathrm{P}<0.01$ vs. HFG group 
Table 1 General characteristics of the different groups of C57BL/6J mice

\begin{tabular}{lllll}
\hline & SCS & HFS & HFG & HFC \\
\hline FBG $(\mathrm{mmo} / \mathrm{L})$ & $5.905 \pm 0.591$ & $6.788 \pm 1.008$ & $6.955 \pm 0.391$ & $6.828 \pm 0.636$ \\
GSP $(\mathrm{mmol} / \mathrm{L})$ & $5.865 \pm 0.490$ & $6.953 \pm 0.536^{\#}$ & $6.897 \pm 0.457^{\#}$ & $6.849 \pm 0.644^{\#}$ \\
TG $(\mathrm{mmo} / \mathrm{L})$ & $1.389 \pm 0.094$ & $1.834 \pm 1.969^{\# \#}$ & $1.773 \pm 0.157^{\# \#}$ & $1.713 \pm 0.165^{\#}$ \\
TC $(\mathrm{mmol} / \mathrm{L})$ & $4.187 \pm 0.189$ & $6.258 \pm 0.529^{\# \#}$ & $6.157 \pm 0.621^{\# \#}$ & $5.107 \pm 0.304^{\# \# *}$ \\
HDL-c $(\mathrm{mmol} / \mathrm{L})$ & $0.536 \pm 0.664$ & $1.117 \pm 0.109^{\# \#}$ & $1.006 \pm 0.258^{\# \#}$ & $0.995 \pm 0.210^{\# \#}$ \\
LDL-c $(\mathrm{mmol} / \mathrm{L})$ & $2.044 \pm 0.127$ & $2.876 \pm 0.226^{\# \#}$ & $2.707 \pm 0.314^{\# \#}$ & $2.821 \pm 0.118^{\# \#}$ \\
\hline
\end{tabular}

FBG fasting blood glucose, GSP glycosylated serum protein, TG triglyceride, TC total cholesterol, HDL-c high-density lipoprotein cholesterol, LDL-c low-density lipoprotein cholesterol. The data are the mean $\pm S D ; n=7$

\#P $<0.05$

$\#$ \# $<0.01$ vs. the SCS group

${ }^{*} \mathrm{P}<0.01$ vs. the HFG group

slowed the daily increase in body weight of HFD-fed mice (Fig. 1d). We also examined the effects of central CTRP4 on peripheral metabolism and found that the levels of fasting plasma glucose, TG, LDL-c, HDL-c, and GSP were not affected by CTRP4 intervention (Table 1). However, TC levels were significantly decreased in mice that received Ad-CTRP4 injection (Table 1).

\section{Effects of central CTRP4 overexpression on hypothalamic leptin signaling}

We investigated the mechanism by which CTRP4 suppressed food intake and found that POMC expression was obviously increased by CTRP4 intervention in the HFD-fed group (Fig. 2a-b), while NPY expression was significantly decreased (Fig. 2c-d). To determine the effect of central Ad-CTRP4 on POMC- and NPYexpressing neurons, we also performed immunofluorescence analysis in mouse hypothalamic tissue. As shown in Fig. 2e-h, CTRP4 overexpression led to a significant increase in the number of POMC-positive cells but a decrease in the number of NPY-positive cells in the ARC. Then, we examined whether central CTRP4 treatment could improve hypothalamic leptin sensitivity in mice with DIO. In standard chow diet-fed mice, there was a rapid and dramatic increase in the phosphorylation of STAT3 and JAK2 following central leptin injection. However, 20 weeks of HFD feeding significantly blunted this response, while central CTRP4 injection completely rescued leptin-induced STAT3 and JAK2 phosphorylation (Fig. 3a-c). In addition, there was a dramatic decrease in the expression of SOCS3 (Fig. 3d-e), an inhibitor of leptin signaling, suggesting that CTRP4 restored leptin sensitivity by inhibiting SOCS3 expression.

\section{Effects of central CTRP4 overexpression on microglial} activation and hypothalamic and peripheral inflammation We then examined whether the improved leptin signaling sensitivity was associated with decreased central inflammation. We measured the expression of hypothalamic TNF- $\alpha$ and IL-6 after i.c.v. Ad-CTRP4 intervention.
As shown in Fig. 4a-d, the protein levels of IL-6 and TNF- $\alpha$ decreased significantly in the hypothalamus after central Ad-CTRP4 intervention. In addition, plasma TNF- $\alpha$ and IL- 6 levels also decreased significantly after central Ad-CTRP4 injection (Fig. 4e-f). Since microglia are the main source of inflammatory cytokines [20], we further evaluated microglial activation in the arcuate nucleus (ARC). Ibal immunostaining revealed that microglial number increased in the ARC of HFD-fed mice, compared with that in SCD-fed controls (Fig. 4g, 4h). Concomitantly, the microglial cell presented with an enlarged and more activated morphology (Fig. 4g, 4i). As shown in Fig. 4g-i, microglial number and cell size decreased after central Ad-CTRP4 injection. Besides, there was a significant increase in the number of Iba1/CD68 colocalized microglia in the ARC (Fig. 4j-k) following HFD-consumption, which was accompanied with increased CD68 protein expression (Fig. 4l-m). After i.c.v. Ad-CTRP4 injection, both Iba1/CD68 colocalization and CD68 protein levels tended to be less (Fig. 4j-m), suggesting that CTRP4 overexpression blunted HFDinduced microglial activation [21].

\section{Effects of central CTRP4 treatment on NF-KB signaling}

As NF- $k B$ signaling is a crucial inflammatory pathway, we next assessed the effects of central CTRP4 on the phosphorylation of P65, inhibitor of NF-kB kinase subunit $\alpha / \beta(\mathrm{IKK} \alpha / \beta)$ and IкB $\alpha$, which are proteins in the NF- $\mathrm{KB}$ signaling cascade, by Western blotting. The phosphorylation of P65 (Fig. 5a-b), IKK $\alpha / \beta$ (Fig. 5g-h), and IKB $\alpha$ (Fig. $5 \mathrm{i}-\mathrm{j}$ ) was dramatically increased by HFD consumption and was inhibited by CTRP4 intervention. Immunofluorescence also clearly demonstrated that there was a significant increase in the number of p-P65 staining in the ARC following HFD consumption, which was attenuated by i.c.v. CTRP4 intervention (Fig. 5k-1). Moreover, Western blot further showed that HFD consumption promoted nuclear translocation of NF-kB P65 from the cytosol to the nucleus, while CTRP4 partly abolished NF- $\mathrm{kB}$ nuclear translocation (Fig. 5c-f). 

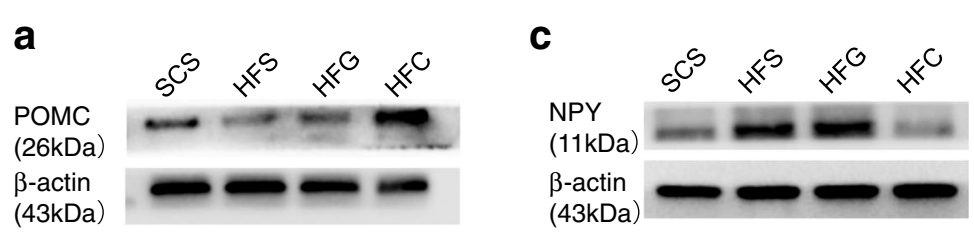

b

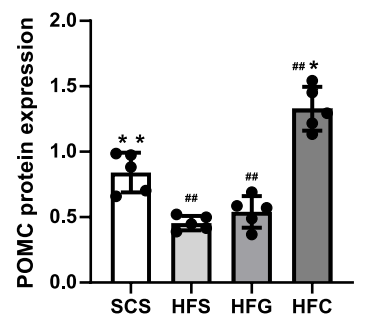

d

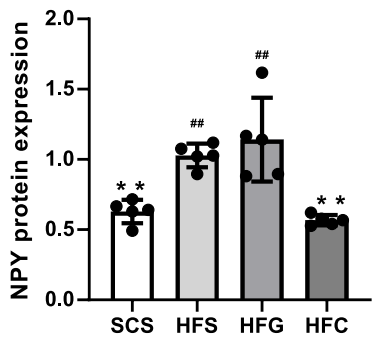

e

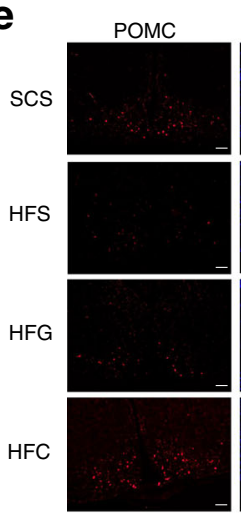

g

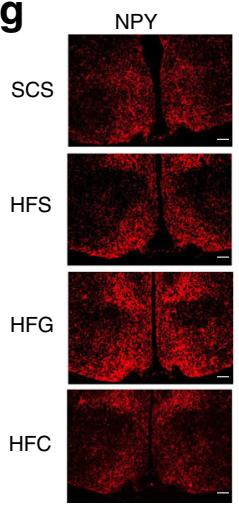

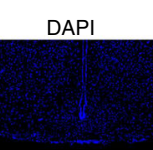
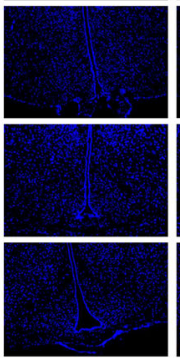

DAPI
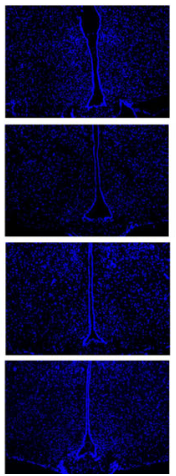

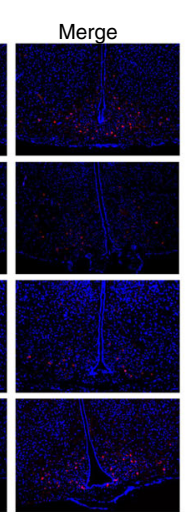

Merge

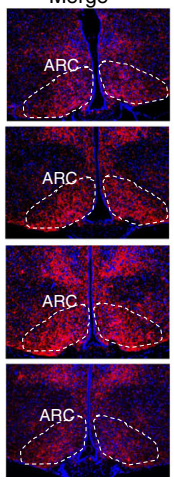

f

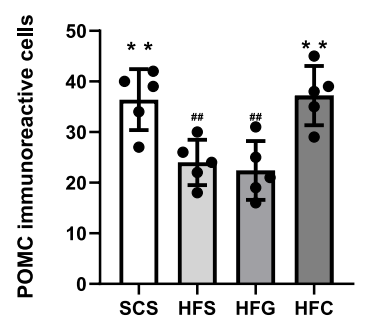

h

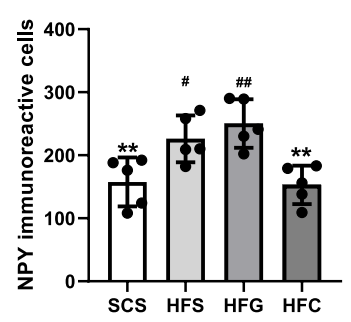

Fig. 2 Effects of central CTRP4 overexpression on hypothalamic neuropeptides by Western blot and immunofluorescence analysis. At $72 \mathrm{~h}$ after i.c.v. injection, the mice receiving saline (SCS and HFS), Ad-GFP (HFG), and Ad-CTRP4 (HFC) were sacrificed, and then the hypothalami were dissected. (a-d) Representative Western blot and quantitative analysis of POMC (a-b) and NPY (c-d) in hypothalami. (e) Representative images of POMC immunoreactivity (red) and DAPI nuclear staining (blue) in the ARCs of mice among groups. (f) Densitometric analysis of POMCimmunoreactive cells among groups. (g) Representative images of NPY immunoreactivity (red) and DAPI nuclear staining (blue) in the ARCs of mice among groups. (h) Densitometric analysis of NPY-immunoreactive cells among groups. $n=5$ per group. Scale bar $=25 \mu m$. Two-way analysis of variance (ANOVA) and Tukey's test for multiple comparisons were used to analyze differences among groups. $P<0.05$, \#P<0.01 vs. SCS group, ${ }^{*} \mathrm{P}<0.05,{ }^{* *} \mathrm{P}<0.01$ vs. HFG group

Effects of CTRP4 on NF-кB signaling in palmitateactivated microglia

To determine the appropriate palmitate concentration to activate microglia, we assessed CD11b expression in BV2 cells treated with different concentrations of palmitate
(50, 100, and $200 \mu \mathrm{M})$. We found that the CD11b protein was most abundant in BV-2 cells exposed to 100 $\mu \mathrm{M}$ PA (Supplementary 1), suggesting that $100 \mu \mathrm{M}$ was the most appropriate concentration to induce microglial activation. Next, BV-2 cells were pretreated with DMSO 


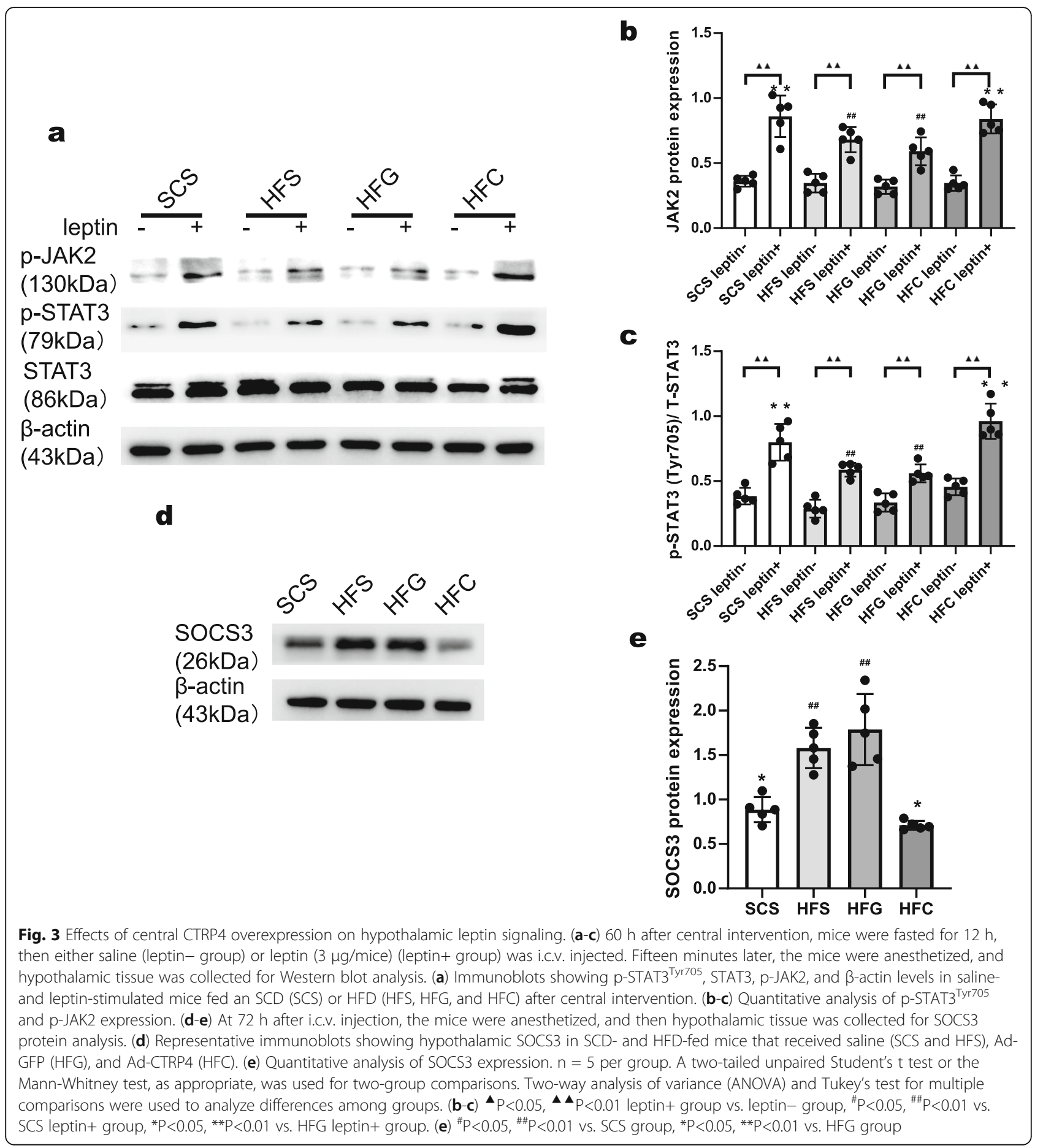

or different concentrations of CTRP4 $(2.5 \mu \mathrm{g} / \mathrm{ml}, 5 \mu \mathrm{g} /$ $\mathrm{ml}$, and $10 \mu \mathrm{g} / \mathrm{ml}$ ) for $2 \mathrm{~h}$, followed by DMSO or palmitate $(100 \mu \mathrm{M})$ treatment for an additional $24 \mathrm{~h}$. Recombinant CTRP4 protein dose-dependently suppressed palmitate-induced CD11b expression (Fig. 6a-b). Moreover, Western blotting showed that CTRP4 reduced PAinduced phosphorylation of $\mathrm{P} 65, \mathrm{IKK} \alpha / \beta$, and IKB $\alpha$, suggesting that the NF- $\kappa \mathrm{B}$ signaling cascade was suppressed by CTRP4 intervention (Fig. 6c-h). Next, we investigated the nuclear translocation of $\mathrm{P} 65$, which is a critical step in the NF- $\mathrm{kB}$ signaling cascade. In the resting state, P65 remained mostly in the cytosol; however, following PA stimulation, P65 was significantly increased in the nucleus. CTRP4 intervention significantly decreased 
a

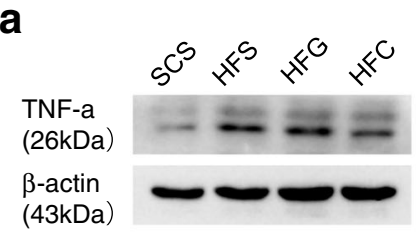

b

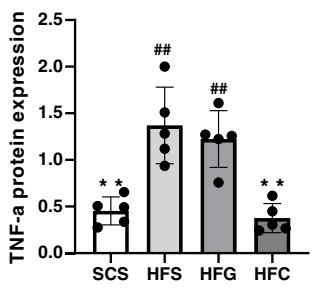

g

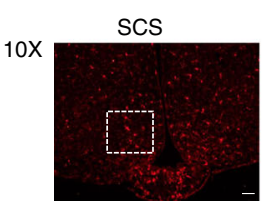

$40 X$
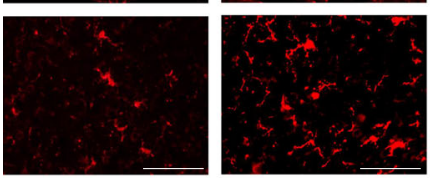

j
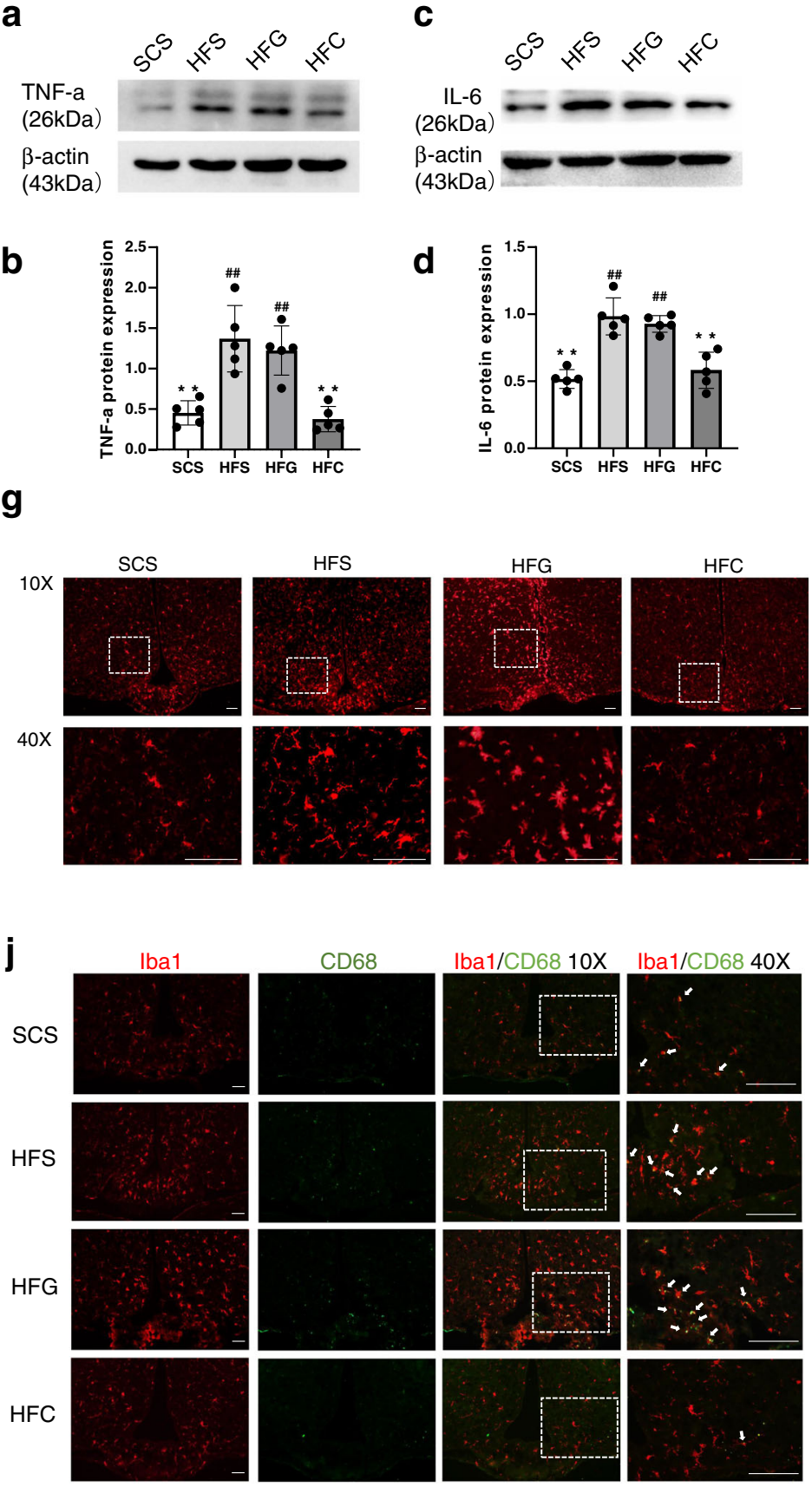

I

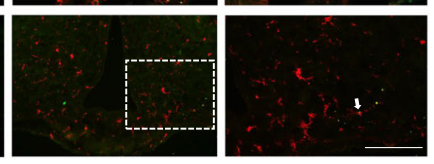

m
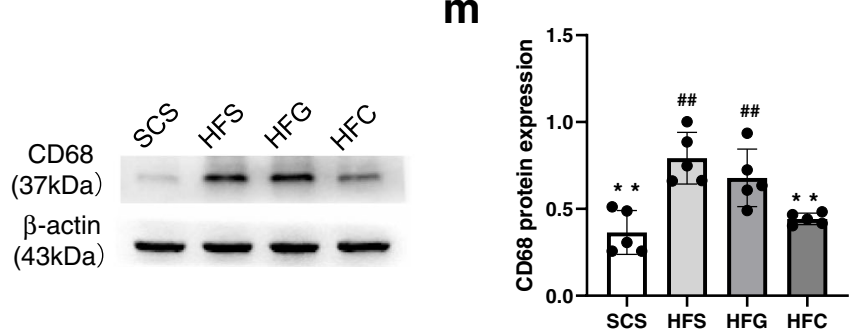

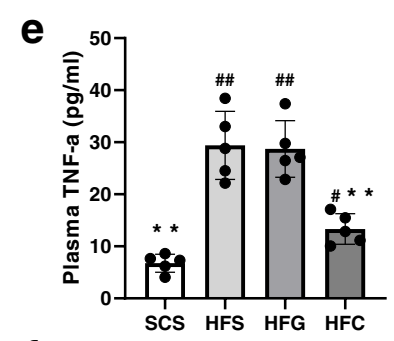

f
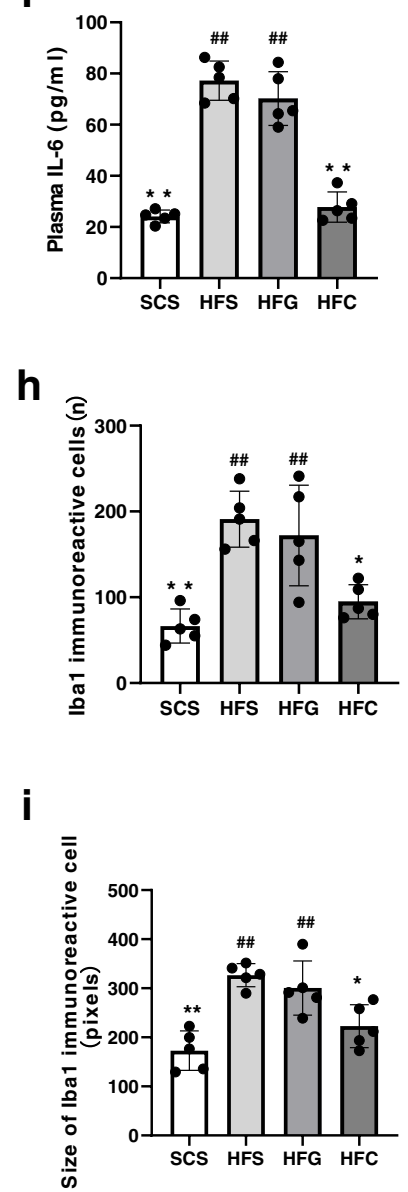

K

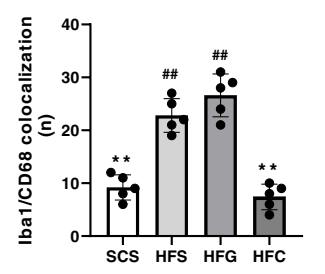

Fig. 4 (See legend on next page.) 
(See figure on previous page.)

Fig. 4 Effects of central CTRP4 overexpression on inflammatory factors and microglial activation. At $72 \mathrm{~h}$ after i.c.v. injection, the mice that received saline (SCS and HFS), Ad-GFP (HFG), and Ad-CTRP4 (HFC) were anesthetized, hypothalamic tissue and blood samples were collected. (ad) Representative immunoblots and quantitative analysis showing hypothalamic TNF-a (a-b) and IL-6 (c-d) in mice among groups. (e-f) Plasma TNF-a (e) and IL-6 (f) levels were measured by ELISA. (g) Representative images of Iba1 immunoreactivity in the ARCs of mice after saline (SCS and HFS), Ad-GFP (HFG), or Ad-CTRP4 intervention (HFC). Mean ARC microglial cell number (h) (per field defined in $\mathbf{g}$ ) and microglia cell size (i) (average number of pixels in 10 largest cells) among the different groups. (j) Immunofluorescence double labeling for CD68(green), Iba1 (red), and colocalization of Iba1/CD68 are shown. (k) Quantitative analysis of the results in panel $\mathbf{j}$. (I-m) Representative Western blot (I) and quantitative analysis of CD68 expression in hypothalami. $n=5$ per group. Scale bar $=25 \mu \mathrm{m}$. Two-way analysis of variance (ANOVA) and Tukey's test for multiple comparisons were used to analyze differences among groups. ${ }^{\# P}<0.05$, ${ }^{\# \#} \mathrm{P}<0.01$ vs. SCS group, ${ }^{*} \mathrm{P}<0.05$, ${ }^{* *} \mathrm{P}<0.01$ vs. HFG group

a

b

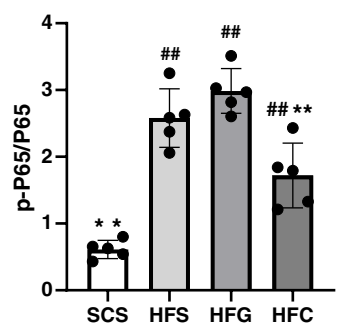

C

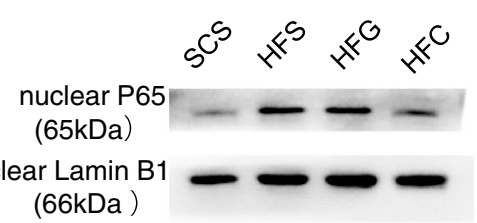

d

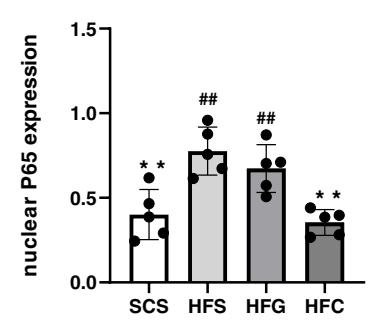

P65 e cytoplasmic P65 $(65 \mathrm{kDa})$

\section{$\beta$-actin}

(43kDa)

$\mathbf{f}$

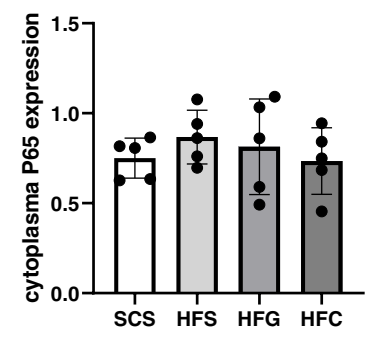

g

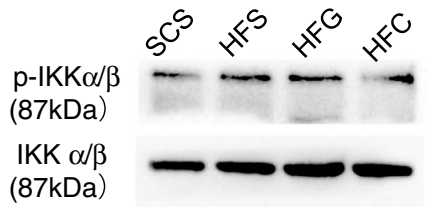

h

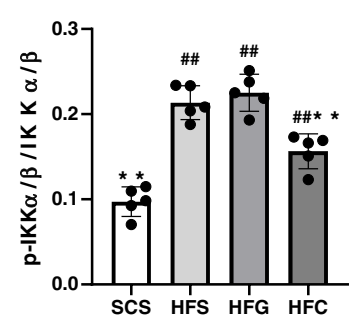

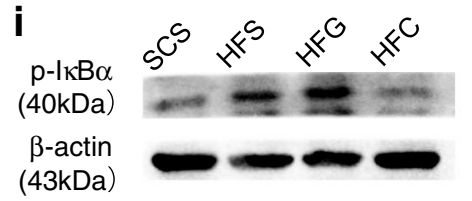

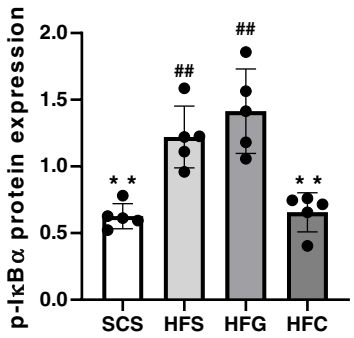

k
SCS
HFS
HFG

HFC
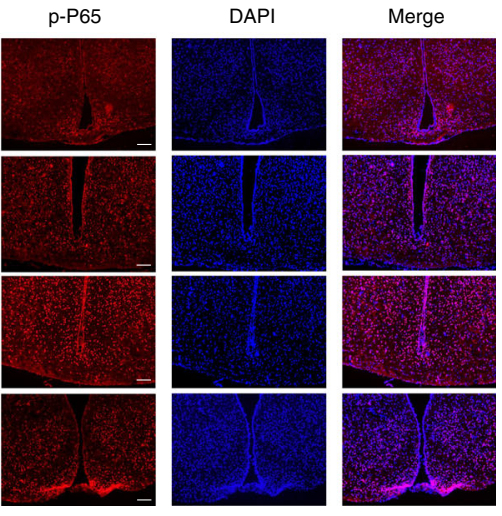

I

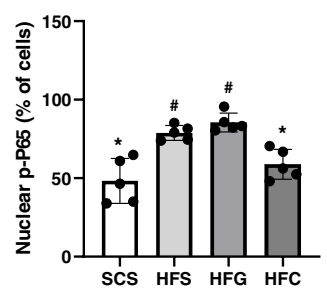

Fig. 5 Effects of central CTRP4 overexpression on hypothalamic NF-KB signaling. At $72 \mathrm{~h}$ after i.c.v. injection, the mice receiving saline (SCS and HFS), Ad-GFP (HFG), and Ad-CTRP4 (HFC) were anesthetized and hypothalamic tissue was collected. (a, c, e, g, i) Representative immunoblots showing hypothalamic total p-P65 and P65 (a), nuclear and cytoplasmic P65 (c, e), p-IKKa/ $\beta$ and IKKa/ $\beta$ (g), and p-IKBa (i) in mice among groups. $(\mathbf{b}, \mathbf{d}, \mathbf{f}, \mathbf{h}, \mathbf{j})$ Quantitative analysis of p-P65 (b), nuclear and cytoplasmic P65 (d, f), p-IKKa/ $\beta$ (h) and p-IKBa (j) protein. (k) Representative images of p-P65 immunoreactivity (red) and DAPI nuclear staining (blue) in the ARCs of mice among groups. (I) Quantitative analysis of the results in panel k. $n=5$ per group. Two-way analysis of variance (ANOVA) and Tukey's test for multiple comparisons were used to analyze differences among groups. ${ }^{\#} \mathrm{P}<0.05,{ }^{\# \#} \mathrm{P}<0.01$ vs. SCS group, ${ }^{*} \mathrm{P}<0.05$, ${ }^{* *} \mathrm{P}<0.01$ vs. HFG group 


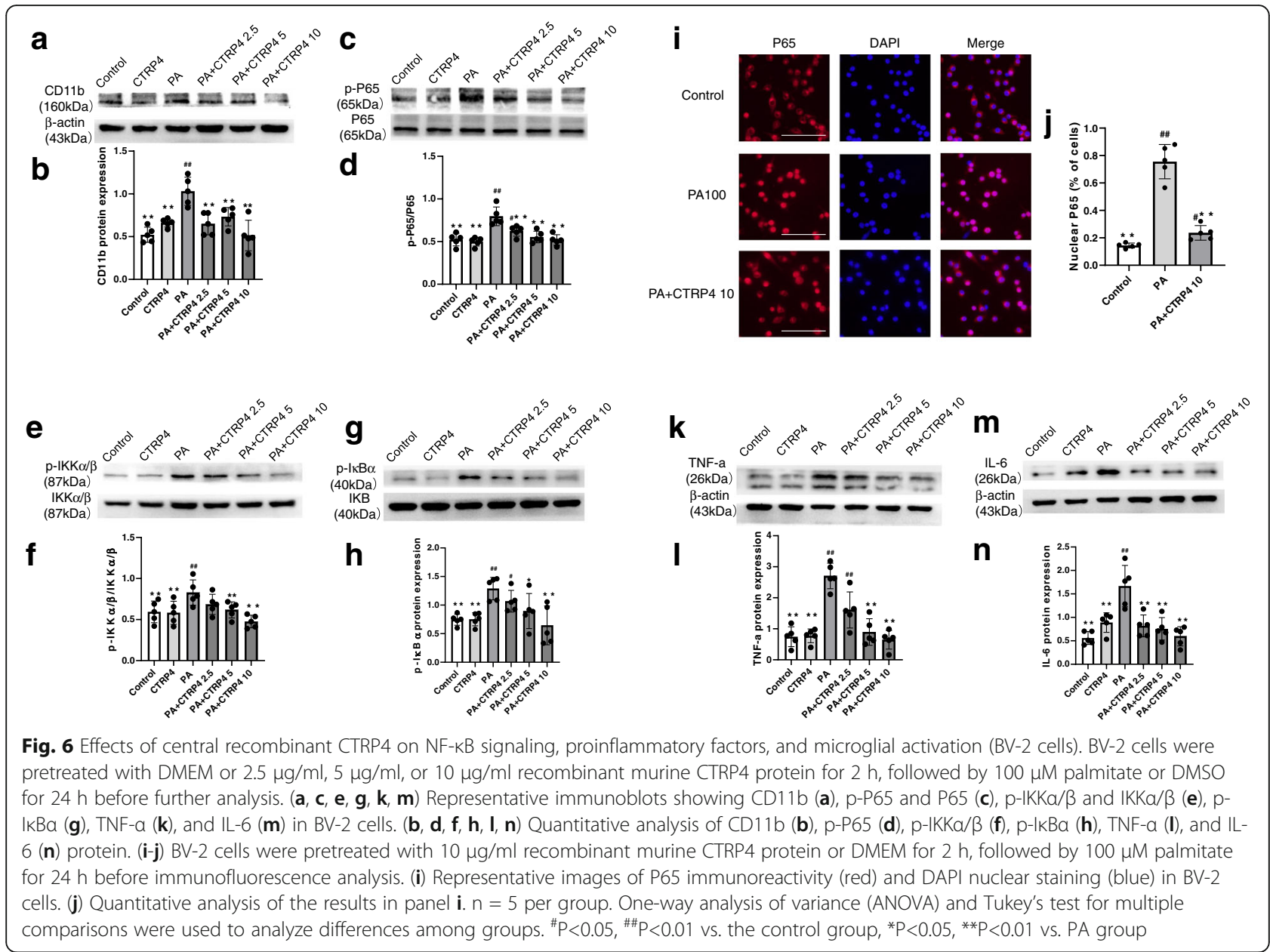

PA-induced P65 nuclear translocation (Fig. 6i-j). We measured the protein expression of proinflammatory cytokines. PA treatment induced the protein expression of TNF- $\alpha$ and IL-6, whereas CTRP4 reduced PA-induced expression of these proinflammatory cytokines (Fig. 6k-n).

\section{Discussion}

The effects of hypothalamic leptin, which mainly occur in the arcuate nucleus, is particularly important in the regulation of energy homeostasis and peripheral metabolism. However, in the context of DIO, leptin resistance develops in the hypothalamus, whereby exogenous leptin cannot phosphorylate STAT3, further disrupting global energy homeostasis. Thus, restoring leptin sensitivity is a topic of interest worldwide. Phenotypically, due to the relatively short observing period [22], the decrease of body weight did not reach statistical significance in the present study. However, hypothalamic CTRP4 overexpression could indeed significantly decrease food intake in HFD-induced obese mice. Mechanistically, central CTRP4 intervention restored the normal response of $p$ STAT3 $^{\text {tyr705 }}$ to exogenous leptin stimulation in obese mice, which was blunted by a HFD, indicating the reestablishment of leptin sensitivity. Furthermore, the expression of SOCS3, a leptin signaling inhibitor, was suppressed by central CTRP4 administration. Taken together, these data suggested that hypothalamic CTRP4 overexpression could improve central leptin signaling and energy homeostasis in mice with DIO.

We further examined the effect of CTRP4 on hypothalamic inflammation, and our results demonstrated that central (hypothalamus) and peripheral (plasma) TNF- $\alpha$ and IL- 6 levels were reduced by central AdCTRP4 intervention. However, the roles of these cytokines in central inflammation differ to some extent. TNF- $\alpha$ is a classic proinflammatory factor that causes hypothalamic insulin and leptin resistance and is believed to be a contributor to the development of obesity [23-25]. On the other hand, the pro- or antiinflammatory role of IL-6 is thought to be contextdependent [26]. However, a recent review suggested that IL-6 could induce marked microglial activation and drive hypothalamic neuroinflammation, indicating that IL-6 is a proinflammatory cytokine in the central nervous 
system [27]. Peripherally, TNF- $\alpha$ and IL-6 are both thought to be proinflammatory cytokines. Previous studies have demonstrated that these factors could be downregulated in the hypothalamus via vagus nerve activation [28]. Acetylcholine, the main neurotransmitter of the vagus nerve, inhibits the production of proinflammatory cytokines through the nicotinic receptor in macrophages $[29,30]$. Interestingly, the excitability of the vagus nerve is decreased in diet-induced obese rodent models [31]. Thus, central CTRP4 overexpression inhibits hypothalamic inflammation and possibly exerts systemic antiinflammatory effects through vagus nerve stimulation.

Chronic HFD feeding leads to low-grade activation of proinflammatory NF- $\mathrm{kB}$ signaling $[8,32,33]$. Previously, neuronal and astrocytic NF- $\mathrm{kB}$ signaling received much attention, as deleting or inhibiting NF- $\mathrm{kB}$ in neurons or astrocytes mitigated DIO [32, 34]. However, microglial $\mathrm{NF}-\mathrm{KB}$ signaling has been found to be critical in the onset of DIO, and selectively restraining microglial NF- $\mathrm{KB}$ signaling greatly reduced microglial activation and limited diet-induced hyperphagia and weight gain [9]. In the present study, both changes in the quantity and size of Iba1-labeled cells and decreased Iba1/CD68 colocalization suggested that central CTRP4 overexpression inhibited HFD-induced microglial activation. Microglia are essential players responsible for increased inflammatory cytokine expression in high-fat environments and are resident immune cells in the brain [4]. Thus, the CTRP4-induced in vivo TNF- $\alpha$ and IL- 6 downregulation observed in our study could be, at least in part, associated with suppressed microglial activation. On the other hand, Western blotting and immunofluorescence results showed that central CTRP4 overexpression blunted the recruitment of the NF- $\mathrm{kB}$ pathway by inhibiting the degradation and phosphorylation of $\mathrm{I} \mathrm{KB}$ and the nuclear translocation of P65 in HFD-fed mice. PA, a common saturated fatty acid in human diets, is accumulated in the hypothalamus after HFD consumption [35]. By using a BV-2 cell model, in vitro data further confirmed that CTRP4 pretreatment could effectively suppress PA-induced NF- $\mathrm{kB}$ signaling cascades and microglial activation, accompanied by decreased production of TNF- $\alpha$ and IL-6, which are targets of NF$\mathrm{\kappa B}$ signaling. Since hypothalamic CTRP4 significantly decreased following HFD consumption, the data in vitro suggested that upregulation of central CTRP4 protein could probably resist HFD-induced microglial NF- $\mathrm{KB}$ activation and obesity. However, the current study could not determine whether the inhibition of NF- $\mathrm{KB}$ signaling only occurred in microglia or in both neuronal and glial cells.

Reactive microgliosis, which is triggered by saturated fatty acids, leads to neuronal injury, and POMC neurons are especially vulnerable to this phenomenon [2, 36-38]. Recent studies have demonstrated that microglia also interfere with nutrient sensing by the hypothalamus, as restraining microglial activation by an NF-kB-dependent method reduces food intake, mitigates DIO and improves leptin signaling $[4,10]$. Our data revealed that central CTRP4 intervention restored leptin signaling and decreased food intake, possibly by suppressing NF$\kappa \mathrm{B}$-dependent microglial activation. However, little is known about the underlying mechanisms [39]. Previous studies suggest the presence of proinflammatory signals or other factors produced by activated microglia that modulate or impair neuronal responsiveness to leptin and regulate energy homeostasis [39, 40]. Among these factors, TNF- $\alpha$ may mediate such microglia-neuronal cross-talk by inducing endoplasmic reticulum stress and inflammatory signaling cascades in appetite-regulating neurons [41]. Therefore, it is possible that CTRP4 acts on metabolism by suppressing microglial activation and TNF- $\alpha$ production. However, other mechanisms might also be involved in this process and contribute to the antiinflammatory and metabolic effects of CTRP4 and should be the focus of future work.

\section{Conclusion}

Taken together, these results indicate that CTRP4 reverses leptin resistance by inhibiting NF-kB-dependent microglial activation and hypothalamic inflammation. The evidence provided in our study suggests that targeting hypothalamic microglia via adipokines may be a promising way to mitigate diet-induced metabolic dysfunction.

\section{Abbreviations}

POMC: Proopiomelanocortin; CART: Cocaine- and amphetamine-regulated transcript; AgRP: Agouti-related peptide; NPY: Neuropeptide Y; HFD: High-fat diet; MBH: Medial basal hypothalamus; TNF-a: Tumor necrosis factor-a; IL6: Interleukin-6; IKK 3 : IKBa kinase $\beta$; IKBa: Inhibitor of KB; NF-KB: Nuclear factor kappa B; CTRP: C1qTNF-related protein; STAT3: Signal transducer and activator of transcription 3; SCD: Standard chow diet; TC: Total cholesterol; TG: Triglycerides; GSP: Glycosylated serum protein; HDL-c: High-density lipoprotein cholesterol; LDL-c: Low-density lipoprotein cholesterol; JAK2: Janus kinase 2; SOCS3: Suppressor of cytokine signaling 3; ARC: Arcuate nucleus; LPS: Lipopolysaccharide; PA: Palmitate

\section{Supplementary Information}

The online version contains supplementary material available at https://doi. org/10.1186/s12974-021-02167-2.

Supplementary 1.

\section{Acknowledgements}

Not applicable.

Authors' contributions

Liu Ye and Yuejie Li conducted the experiments. Gongwei Jia and Ying Wang analyzed the Data. Dandong Wu and Lehua Yu designed the study and drafted the article. Hong Chen revised the article. All authors critically 
reviewed the manuscript. All authors read and approved the final manuscript.

\section{Funding}

This study was funded by the Natural Science Foundation of China (No 81600615 and No. 82072543).

\section{Availability of data and materials}

The datasets used and/or analyzed during the current study are available from the corresponding author on reasonable request.

\section{Declarations}

Ethics approval and consent to participate

All animal protocols were approved by the Animal Experimentation Ethics Committee of Chongqing Medical University.

\section{Consent for publication}

Not applicable.

\section{Competing interests}

The authors declare that they have no competing interests.

\section{Author details}

${ }^{1}$ Department of Rehabilitation, The Second Affiliated Hospital of Chongqing Medical University, 76 Linjiang Road, Yuzhong District, Chongqing 400010, China. ${ }^{2}$ Department of Orthopedics, The First Affiliated Hospital of Chongqing Medical University, Chongqing, China.

\section{Received: 14 January 2021 Accepted: 5 May 2021}

\section{Published online: 18 July 202}

\section{References}

1. Varela L, Horvath TL. Leptin and insulin pathways in POMC and AgRP neurons that modulate energy balance and glucose homeostasis. EMBO Rep. 2012;13(12):1079-86. https://doi.org/10.1038/embor.2012.174.

2. Thaler JP, Yi CX, Schur EA, Guyenet SJ, Hwang BH, Dietrich MO, et al. Obesity is associated with hypothalamic injury in rodents and humans. J Clin Invest. 2012;122(1):153-62. https://doi.org/10.1172/JCl59660.

3. Waise TM, Toshinai K, Naznin F, NamKoong C, Md Moin AS, Sakoda H, et al. One-day high-fat diet induces inflammation in the no dose ganglion and hypothalamus of mice. Biochem Biophys Res Commun. 2015;464(4):115762. https://doi.org/10.1016/j.bbrc.2015.07.097.

4. Valdearcos M, Robblee MM, Benjamin DI, Nomura DK, XU AW, Koliwad SK Microglia dictate the impact of saturated fat consumption on hypothalamic inflammation and neuronal function. Cell Rep. 2014;9(6):2124-38. https://doi. org/10.1016/j.celrep.2014.11.018.

5. Berkseth KE, Guyenet SJ, Melhorn SJ, Lee D, Thaler JP, Schur EA, et al. Hypothalamic gliosis associated with high-fat diet feeding is reversible in mice: a combined immunohistochemical and magnetic resonance imaging study. Endocrinology. 2014;155(8):2858-67. https://doi.org/10.1210/en.2014-1121.

6. Hayden MS, Ghosh S. Shared principles in NF-kappaB signaling. Cell. 2008; 132(3):344-62. https://doi.org/10.1016/j.cell.2008.01.020.

7. Naznin F, Toshinai K, Waise TM, NamKoong C, Md Moin AS, Sakoda H, et al. Diet-induced obesity causes peripheral and central ghrelin resistance by promoting inflammation. J Endocrinol. 2015;226(1):81-92. https://doi.org/1 0.1530/JOE-15-0139.

8. Zhang X, Zhang G, Zhang H, Karin M, Bai H, Cai D. Hypothalamic IKKbeta/ NF-kappaB and ER stress link overnutrition to energy imbalance and obesity. Cell. 2008;135(1):61-73. https://doi.org/10.1016/j.cell.2008.07.043.

9. Valdearcos M, Douglass JD, Robblee MM, Dorfman MD, Stifler DR, Bennett $M L$, et al. Microglial inflammatory signaling orchestrates the hypothalamic immune response to dietary excess and mediates obesity susceptibility. Cell Metab. 2017:26:185-197.e3.

10. André C, Guzman-Quevedo O, Rey C, Rémus-Borel J, Clark S, CastellanosJankiewicz A, et al. Inhibiting microglia expansion prevents diet-induced hypothalamic and peripheral inflammation. Diabetes. 2017;66(4):908-19. https://doi.org/10.2337/db16-0586.

11. Schäffler A, Schölmerich J, Salzberger B. Adipose tissue as an immunological organ: toll-like receptors, C1q/TNFs and CTRPs. Trends Immunol. 2007;28(9): 393-9. https://doi.org/10.1016/j.it.2007.07.003.
12. Kishore U, Gaboriaud C, Waters P, Shrive AK, Greenhough TJ, Reid KB, et al. $\mathrm{Clq}$ and tumor necrosis factor superfamily: modularity and versatility. Trends Immunol. 2004;25(10):551-61. https://doi.org/10.1016/j.it.2004.08.006.

13. Wong GW, Krawczyk SA, Kitidis-Mitrokostas C, Ge G, Spooner E, Hug C, et al. Identification and characterization of CTRP4, a novel secreted glycoprotein, from adipose tissue that reduces serum glucose in mice and forms heterotrimers with adiponectin. FASEB J. 2009;23(1):241-58. https://doi.org/1 0.1096/fj.08-114991.

14. Lee W, Kim MJ, Park EJ, Choi YJ, Park SY. C1qTNF-related protein-6 mediates fatty acid oxidation via the activation of the AMP-activated protein kinase. FEBS Lett. 2010; 584:968-972, 5, doi: https://doi.org/10.1016/j.febslet.2010.01.040.

15. Wang XQ, Liu ZH, Xue L, Lu L, Gao J, Shen Y, et al. C1q/TNF-related protein 1 links macrophage lipid metabolism to inflammation and atherosclerosis. Atherosclerosis. 2016;250:38-45. https://doi.org/10.1016/j.atherosclerosis.201 6.04.024.

16. Byerly MS, Petersen PS, Ramamurthy S, Seldin MM, Lei X, Provost E, et al. C1q/TNF-related protein 4 (CTRP4) is a unique secreted protein with two tandem C1q domains that functions in the hypothalamus to modulate food intake and body weight. J Biol Chem. 2014;289(7):4055-69. https://doi.org/1 $0.1074 / j b c . M 113.506956$

17. Luo Y, Wu X, Ma Z, Tan W, Wang L, Na D, et al. Expression of the novel adipokine C1qTNF-related protein 4 (CTRP4) suppresses colitis and colitisassociated colorectal cancer in mice. Cell Mol Immunol. 2016;13(5):688-99. https://doi.org/10.1038/cmi.2016.16.

18. Li Y, Ye L, Jia G, Chen H, Yu L, Wu D. C1q/TNF-related protein 4 induces signal transducer and activator of transcription 3 pathway and modulates food intake. Neuroscience. 2020;429:1-9. https://doi.org/10.1016/j. neuroscience.2019.12.039.

19. Folgueira C, Beiroa D, González-Rellán MJ, Porteiro B, Milbank E, Castelao C, et al. Uroguanylin improves leptin responsiveness in diet-induced obese mice. Nutrients. 2019;11(4):752. https://doi.org/10.3390/nu11040752.

20. Hanisch UK. Microglia as a source and target of cytokines. Glia. 2002;40(2): 140-55. https://doi.org/10.1002/glia.10161.

21. Gao Y, Ottaway N, Schriever SC, Legutko B, García-Cáceres C, de la Fuente E, et al. Share Hormones and diet, but not body weight, control hypothalamic microglial activity. Glia. 2014;62(1):17-25. https://doi.org/10.1002/glia.22580.

22. Zhou M, Xu X, Wang $H$, Yang G, Yang $M$, Zhao X, et al. Effect of central JAZF1 on glucose production is regulated by the PI3K-Akt-AMPK pathway. FASEB J. 2020;34(5):7058-74. https://doi.org/10.1096/fj.201901836RR.

23. Miyazaki $Y$, Pipek $R$, Mandarino $\sqcup$, DeFronzo RA. Tumor necrosis factor alpha and insulin resistance in obese type 2 diabetic patients. Int J Obes Relat Metab Disord. 2003;27(1):88-94. https://doi.org/10.1038/sj.ijo.0802187.

24. Picardi PK, Caricilli AM, de Abreu LL, Carvalheira JB, Velloso LA. Saad MJ. Modulation of hypothalamic PTP1B in the TNF-alpha-induced insulin and leptin resistance. FEBS Lett. 2010;584:3179-3184, 14, doi: https://doi.org/10.1 016/j.febslet.2010.05.064

25. Gao $Y$, Han $C$, Huang $H, X i n Y, X u Y$, , Luo L, et al. Heat shock protein 70 together with its co-chaperone CHIP inhibits TNF-alpha induced apoptosis by promoting proteasomal degradation of apoptosis signal-regulating kinase1. Apoptosis. 2010;15(7):822-33. https://doi.org/10.1007/s10495-010-0495-7.

26. Hunter CA, Jones SA. IL-6 as a keystone cytokine in health and disease. Nature Immunology. 2015;16(5):448-57. https://doi.org/10.1038/ni.3153.

27. Bobbo VCD, Jara CP, Mendes NF, Morari J, Velloso LA, Araújo EP. Interleukin6 expression by hypothalamic microglia in multiple inflammatory contexts: a systematic review. Biomed Res Int. 2019;22:1365210.

28. Guijarro A, Laviano A, Meguid MM. Hypothalamic integration of immune function and metabolism. Prog Brain Res. 2006;153:367-405. https://doi. org/10.1016/S0079-6123(06)53022-5.

29. Wang H, Yu M, Ochani M, Amella CA, Tanovic M, Susarla S, et al. Nicotinic acetylcholine receptor alpha7 subunit is an essential regulator of inflammation. Nature. 2003:421(6921):384-8. https://doi.org/10.1038/nature01339.

30. Ulloa $L$. The vagus nerve and the nicotinic anti-inflammatory pathway. Nat Rev Drug Discov. 2005;4(8):673-84. https://doi.org/10.1038/nrd1797.

31. Browning KN, Fortna SR, Hajnal A. Roux-en-Y gastric bypass reverses the effects of diet-induced obesity to inhibit the responsiveness of central vagal motoneurones. J Physiol. 2013;591(9):2357-72. https://doi.org/10.1113/ jphysiol.2012.249268

32. Benzler J, Ganjam GK, Pretz D, Oelkrug R, Koch CE, Legler K, et al. Central inhibition of IKKb/NF-kB signaling attenuates high-fat diet-induced obesity and glucose intolerance. Diabetes. 2015;64(6):2015-27. https://doi.org/10.233 7/db14-0093. 
33. Tsaousidou E, Paeger L, Belgardt BF, Pal M, Wunderlich CM, Brönneke $H$, et al. Distinct roles for JNK and IKK activation in agouti-related peptide neurons in the development of obesity and insulin resistance. Cell Rep. 2014;9(4):1495-506. https://doi.org/10.1016/j.celrep.2014.10.045.

34. Douglass JD, Dorfman MD, Fasnacht R, Shaffer LD, Thaler JP. Astrocyte IKKb/ NF-kB signaling is required for diet-induced obesity and hypothalamic inflammation. Mol Metab. 2017;6(4):366-73. https://doi.org/10.1016/j. molmet.2017.01.010.

35. Duffy $C M$, Yuan C, Wisdorf LE, Billington CJ, Kotz CM, Nixon JP, et al. Role of orexin A signaling in dietary palmitic acid-activated microglial cells. Neurosci Lett. 2015;606:140-4. https://doi.org/10.1016/j.neulet.2015.08.033.

36. Milanski M, Degasperi G, Coope A, Morari J, Denis R, Cintra DE, et al. Saturated fatty acids produce an inflammatory response predominantly through the activation of TLR4 signaling in hypothalamus: implications for the pathogenesis of obesity. J Neurosci. 2009;29(2):359-70. https://doi.org/1 0.1523/JNEUROSCI.2760-08.2009.

37. Block ML, Hong JS. Chronic microglial activation and progressive dopaminergic neurotoxicity. Biochem Soc Trans. 2007;35(5):1127-32. https:// doi.org/10.1042/BST0351127.

38. Yi CX, Walter M, Gao Y, Pitra S, Legutko B, Kälin S, et al. TNFa drives mitochondrial stress in POMC neurons in obesity. Nat Commun. 2017;8(1): 15143. https://doi.org/10.1038/ncomms15143.

39. Douglass JD, Dorfman MD, Thaler JP. Glia: silent partners in energy homeostasis and obesity pathogenesis. Diabetologia. 2017;60(2):226-36. https://doi.org/10.1007/s00125-016-4181-3.

40. Reis WL, Yi CX, Gao Y, Tschöp MH, Stern JE, et al. Brain innate immunity regulates hypothalamic arcuate neuronal activity and feeding behavior. Endocrinology. 2015;156(4):1303-15. https://doi.org/10.1210/en.2014-1849.

41. Dalvi PS, Chalmers JA, Luo V, Han DY, Wellhauser L, Liu Y, et al. High fat induces acute and chronic inflammation in the hypothalamus: effect of high-fat diet, palmitate and TNF-a on appetite-regulating NPY neurons. Int 」 Obes (Lond). 2016:41:149-58.

\section{Publisher's Note}

Springer Nature remains neutral with regard to jurisdictional claims in published maps and institutional affiliations.

Ready to submit your research? Choose BMC and benefit from:

- fast, convenient online submission

- thorough peer review by experienced researchers in your field

- rapid publication on acceptance

- support for research data, including large and complex data types

- gold Open Access which fosters wider collaboration and increased citations

- maximum visibility for your research: over $100 \mathrm{M}$ website views per year

At $\mathrm{BMC}$, research is always in progress.

Learn more biomedcentral.com/submissions 